\title{
Stability Evaluation of Deformation (Denudation) of Yuanjue Rock Cave Roof Based on Multisource Monitoring
}

\author{
Zhigang Tao $\mathbb{D}^{1,,^{1,2,3}}$ Senlin Luo, ${ }^{1,2}$ Di Wu $\mathbb{D}^{1,2}$ Yafei Qiao ${ }^{10},{ }^{3,4}$ Gang Zhao, ${ }^{5}$ \\ and Zhigang Meng $\mathbb{D D}^{1,2}$ \\ ${ }^{1}$ State Key Laboratory for Geomechanics and Deep Underground Engineering, Beijing 100083, China \\ ${ }^{2}$ School of Mechanics and Civil Engineering, China University of Mining and Technology, Beijing 100083, China \\ ${ }^{3}$ Key Laboratory of Geotechnical and Underground Engineering (Tongji University), Ministry of Education, \\ Shanghai 200092, China \\ ${ }^{4}$ Department of Geotechnical Engineering, College of Civil Engineering, Tongji University, Shanghai 200092, China \\ ${ }^{5}$ Academy of Dazu Rock Carving, Chongqing 402360, China
}

Correspondence should be addressed to Zhigang Tao; taozhigang@cumtb.edu.cn

Received 19 May 2020; Revised 15 October 2020; Accepted 27 October 2020; Published 8 December 2020

Academic Editor: Zhixiong Li

Copyright (C) 2020 Zhigang Tao et al. This is an open access article distributed under the Creative Commons Attribution License, which permits unrestricted use, distribution, and reproduction in any medium, provided the original work is properly cited.

The grotto rock mass is a type of cave structure, formed under the complex forces of environment, geology, and human interventions. Many scholars have carried out a lot of work in the protection of cultural relics. However, the research on detection and monitoring methods based on the parametric evolution system remains incomplete. In recent years, with the intersection and integration of disciplines, IoT (IoT: Internet of Things) systems and sensor technologies have developed rapidly. Under this background, a new monitoring system suitable for the protection of cultural relics was independently developed and applied to the protection and research work of Yuanjue rock cave, and the system was corrected and improved in practice. In this paper, according to the complex force characteristics of the sandstone roof of the Yuanjue rock cave at Dazu Rock Carvings and the geological conditions. Initially, a detailed survey of the geological conditions of the Yuanjue rock cave area was conducted; furthermore, according to the unique structural and load characteristics of the outer and inner surfaces of the roof, the monitoring methods and principles of each main control factor were explored, while the layout of monitoring points was optimized; finally, based on the microsensing technology, intelligent high-precision sensing hardware was installed and debugged for each main control factor, while the network was formed to form a multisource monitoring IoT system for the roof stability of the circular sense hole. After nearly half a year of continuous monitoring, the deformation and denudation rules of the roof of Yuanjue Cave were revealed, and a new approach of evaluating roof stability was proposed. This research provided technical support and research ideas for monitoring the stability of similar cultural relics.

\section{Introduction}

The grotto rock mass is a type of cave structure under the complex forces of environment, geology, and human interventions. The grottoes in China were first built in Xinjiang in the 3rd century A.D. and were developed eastwards along the Silk Road with Buddhism. In the 4th century, the Mogao Grottoes in Dunhuang of Gansu Province was built, during the 5th-6th century. The development reached its peak at the north and central plains [1]. Since 1949, in China, a high amount of research work on the protection and mechanism of grottoes and temples was carried out, while many exemplary results were achieved. As an example, Zhang et al. [2], the micro- and mechanical properties of Dafowan stone carving in Dazu were studied through X-ray diffraction and optical microscopy; Fu Changhua et al. studied the Mogao Grottoes in Dunhuang and analyzed the possible damage caused by earthquakes to the cave surrounding rocks and auxiliary structures through the dynamic finite element method [3]; Gao Bingli et al. utilized factor investigation and 
mechanical calculation, along with monitoring and analysis to study the development mechanism and law of roof cracks [4]; Ding Wuxiu et al. utilized survey methods to study the weathering characteristics and influencing factors of the surrounding rocks of Longmen Grottoes in Luoyang [5]; Wang Zhiyin et al. performed numerical simulation and inversion analysis of the rheological fracture process of No. 5 hole, while obtaining rheological parameters and the best combination of other sensitive parameters based on the maximum tensile stress tracking method and the inverse numerical model of the rock fracture process [6]; Li Lihui et al. studied the surrounding rock surface in Longyou Grottoes, along with the weathering speed of the surrounding rock utilizing the compression molding method [7]; however, the research on detection and monitoring methods based on the parameter evolution system was not perfect in results. At present, with the development of the Internet of Things and sensor technology, the level of monitoring and prediction of rock mass stability has been highly improved.

Yuanjue rock cave constitutes one of the most representative works of Baoding Mountain Cliff Statue, located on the south cliff of Dafowan in Baoding Mountain. Unlike other statues in Dafowan, Yuanjue rock cave is a rare cave that follows the cave shapes from Buddhist statues in northern China that exist in Dafowan [8]. For thousands of years, under the influence of long-term natural forces, especially in recent years, the increase of atmospheric precipitation and groundwater seepage, as well as pollution due to the high number of tourists, have led to a series of changes in the surrounding environment of the cave [9-11]. The Yuanjue cave cultural relic body and the surrounding rock mass presented a series of problems, such as accelerated weathering, denudation, and crack generation [12-15], along with increased roof instability [16-19].

In view of the complex stress characteristics and geological environment conditions of the sandstone roof of Yuanjue rock cave in Dazu Rock Carvings, as presented in this paper, a detailed investigation of the regional geological conditions of Yuanjue rock cave was conducted, while the structural composition, failure characteristics, and stable main control factors of the sandstone roof were analyzed; subsequently, according to the unique structural characteristics and load characteristics of the outer and inner surface of the roof, the monitoring methods and principles of each main control factor were explored, respectively, while the layout of monitoring points was optimized; finally, based on the microsensing technology, the intelligent highprecision sensor hardware of each main control factor was installed and debugged, forming a multisource monitoring object network system for the stability of the cave roof, which was similar to the cultural relic rock mass stability monitoring, which provided technical support.

\section{Geological Conditions of Yuanjue Rock Cave}

Dazu Rock Carvings were composed of cliff statues and inscriptions of Beishan, Baoding, Nanshan, Shizhuan, and Shimen mountains. More than 50,000 statues of Buddhism,
Taoism, and Confucianism existed. Dazu Rock Carvings were first carved in the first year of Yonghui in the early Tang Dynasty. These carvings increased during the late Tang Dynasty and the Five Dynasties, as well as during the Ming and Qing Dynasties. The Dazu Rock Carvings constitute a representative work of the late Chinese Grottoes as temple art, which are famous for the corresponding sized, exquisite carving, various themes, rich connotations, and successful preservation.

Yuanjue rock cave is located in the western part of the south cliff of Baoding Dafowan. It was one of the most representative works of carving in Baoding Mountain Cliff Statue.

2.1. Meteorological and Hydrogeological Features. The climate of Dazu area is a subtropical warm and humid monsoon climate, with four distinct seasons, but less extreme weather, high precipitation, and high humidity. The average annual rainfall is approximately $1000 \mathrm{~mm}$; Dazu district is located on the watershed of Fujiang and Tuo rivers, which constitutes the origin of the Xi River. The Laixi River and the Huaiyuan River, while two other main rivers in the territory flow overseas, with very low water quantities. At present, the water in the area is entirely supplied by artificial isolation and atmospheric precipitation. The fracture water existence within the fractures of the sandstone is proven to damage the stone carvings.

2.2. Formation Lithology and Geological Structure. The exposed strata in Dafowan stone carving area are sedimentary rocks, according to the previous drilling and exploration results. The upper layer is mainly light brown to grayish green fine-grained sandstone for 20 meters, while the lower layer is mainly dark red mudstone and grayish-green sandstone with medium-thick layered interbedding, occasionally occurring as dark green mudstone. The characteristics of hard and soft rocks in the area resulted in the steep cliffs of Dafowan and to its surrounding areas, while many unique geological and geomorphic forms of collapses exist; the strata in the rock carving area are mainly the upper part of Suining Formation and the lower part of Penglaizhen formation of Upper Jurassic, which was formed during the Middle Jurassic period. The lithology of the stratum is relatively simple, the stratum is nearly horizontal, and the influence of geological structure to the morphology is low. One of the main factors that affected the stability of Yuanjue rock cave was the large-scale joint fissures. Yuanjue rock cave is located in the block structure formed by three groups of fissures J-01, J-04, and J-10 and the cliff. These fissures are also the seepage channels of the surrounding rock of Yuanjue rock cave, resulting in the deterioration, weathering, and denudation of the rock mass, as presented in Figure 1.

\section{Monitoring Method and Principle of Surrounding Rock Stability of Yuanjue Rock Cave}

In this study, the multisource monitoring method was utilized to monitor the stability and deformation of the surrounding rock of Yuanjue rock cave. According to the monitoring results, the deformation mechanism of the roof 


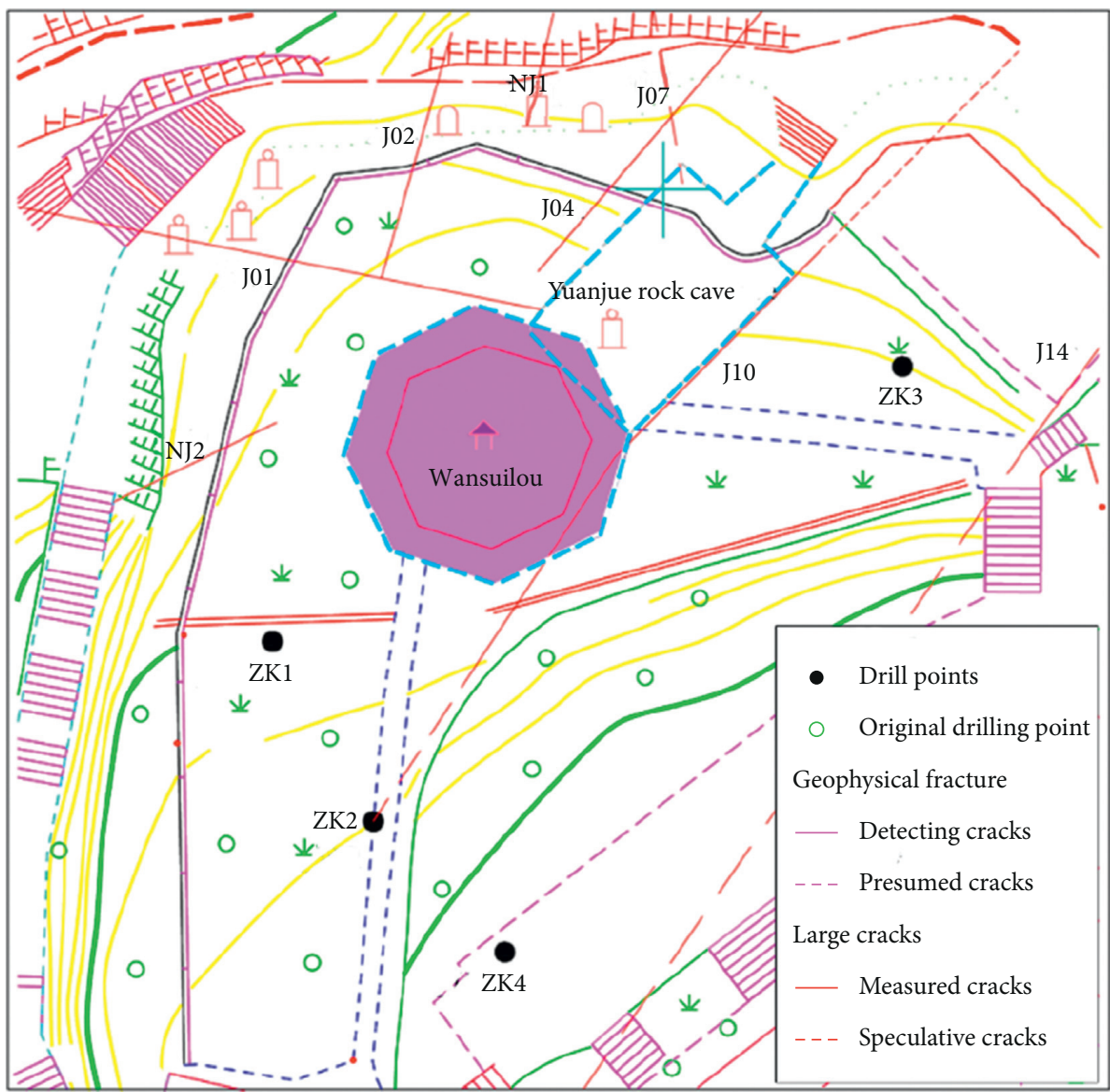

Figure 1: Distribution of fissures of Yuanjue rock cave within Dafowan.

of Yuanjue rock cave was comprehensively analyzed. The main monitoring contents were roof pressure, grating measurement of roof deformation, GNSS (GNSS: Global Navigation Satellite System), and laser monitoring of denudation amount. The layout of each measuring point is presented in Figure 2.

3.1. Pressure Monitoring of Cave Roof. High-precision quartz piezoelectric sensors were utilized in the stress monitoring equipment. The sensors were string piezoelectric sensors, which were set with multiple strings, to accurately measure the pressure under eccentric load. This type of sensor had the advantages of high sensitivity, high precision, and high stability, proving suitable for long-term observations. According to the position of support and beam, 11 stress monitoring points were arranged, as presented in Figure 2.

3.2. Grating Measurement of Roof Deformation. Grating monitoring was utilized to monitor the deformation of the external surface of the cave roof, artificial miscellaneous fills, and quaternary overburden on the top surface of stripped roof rock; fixed-point fixture was utilized to fix and install 1 longitudinal and 2 transverse fixed-point gratings on the bedrock, while at the same time, the 1 vertical and 2 horizontal fixed-point gratings were installed at the fixed-point fixture on the cave roof. The entire section real-time monitoring was formed on the upper and lower rock layers of the slate layer on the dome roof in a network format. The fixed-point spacing was designed to be of $1 \mathrm{~m}$. According to the layout area of $10 \times 12 \mathrm{~m}$, a total of 35 measuring points was designed for every 1 longitudinal and 2 transverse fixed gratings, with a total of 70 measuring points. The distribution characteristics of monitoring points are presented in Figure 3.

3.3. GNSS Monitoring on Surface. GNSS monitoring utilized GNSS to provide three-dimensional coordinates and speed information of the ground monitoring point under all weather conditions. GNSS was equipped with 3 sets of equipment ( 1 reference station +2 monitoring stations). The layout of measuring points is presented in Figure 2. Only the monitoring station data was updated in the data result. The reference station was preset with the coordinates remaining unchanged, while the relative displacement of each monitoring point could be calculated according to the coordinates of the base station.

3.4. Laser Monitoring of Denudation Amount. The customdeveloped laser automatic ranging system was mainly utilized to monitor the weathering and denudation rate of the 


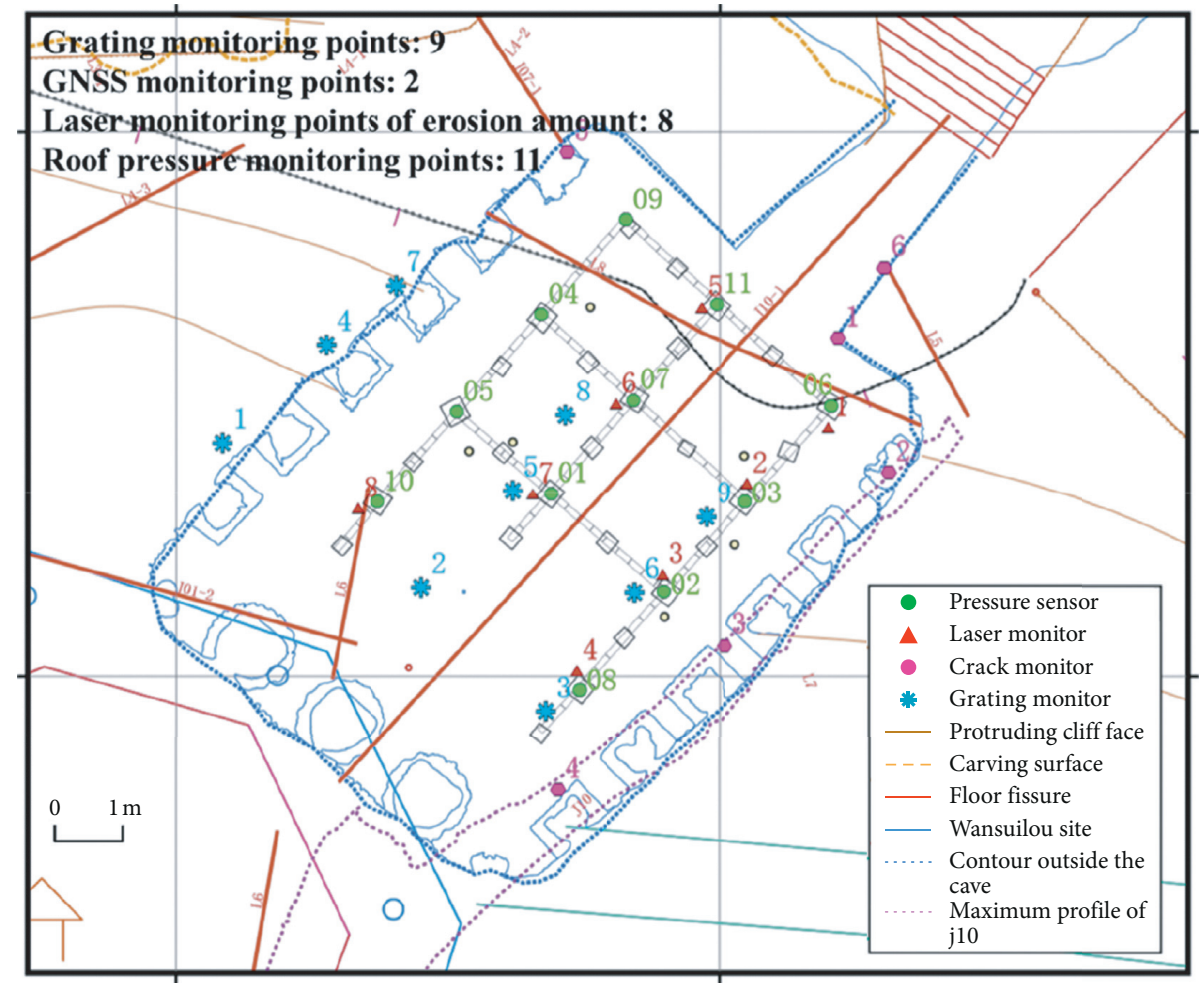

FiguRe 2: Layout of measuring points of Yuanjue rock cave within Dafowan.

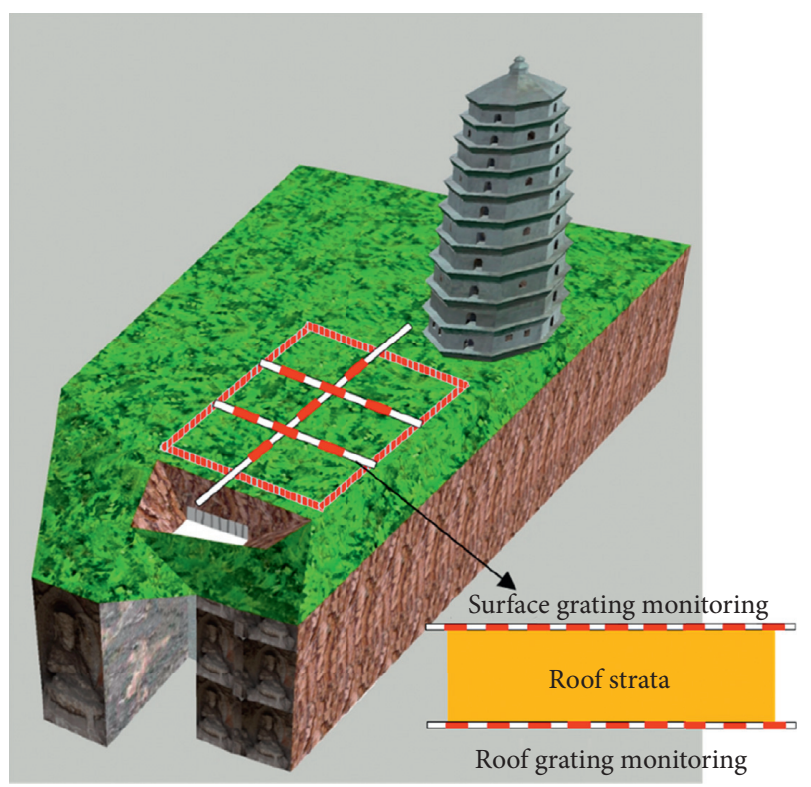

FIGURE 3: Schematic diagram of the grating layout.

inner surface of the dome roof slab. The acquisition frequency was once every hour, which was transmitted to the remote laboratory warning platform. A total of 10 measurement points was arranged at this time frame (the measurement points were arranged according to the distribution of the roof wet zone, the characteristics of the stripping form, and the historical stripping position).
Denudation laser monitoring system was mainly composed of laser automatic rangefinder. The laser rangefinder utilized the high-frequency monochromatic laser to measure the noncontact distance of the point target, while the point to be measured did not require special treatment. Consequently, it could directly measure the initial surface. The triangulation method was adopted to measure the distance, while the principle of the triangulation method is presented in Figure 1. The laser emitted the excitation light, whereas after the object was irradiated, the reflected light was transmitted by the linear CCD (CCD: Charge-coupled Device) receiver because the laser and detector were dispersed within a certain distance; according to the optical path, objects of different distances would be imaged at different positions on the CCD. According to the trigonometric formula, the distance of the object to be measured could be deduced. The measurement accuracy could reach $0.01 \mathrm{~mm}$. Under the condition of accuracy achievement, the distance between the laser source and the point to be measured should be maintained within $250 \mathrm{~mm}$. The principle is presented in Figure 4.

\section{Monitoring Data Analysis}

The roof deformation was comprehensively monitored through the multisource monitoring method [20]. The system principle is presented in Figure 5. The data detected by each monitoring point were transmitted to the monitoring and prediction center via the base station through wireless transmission. 


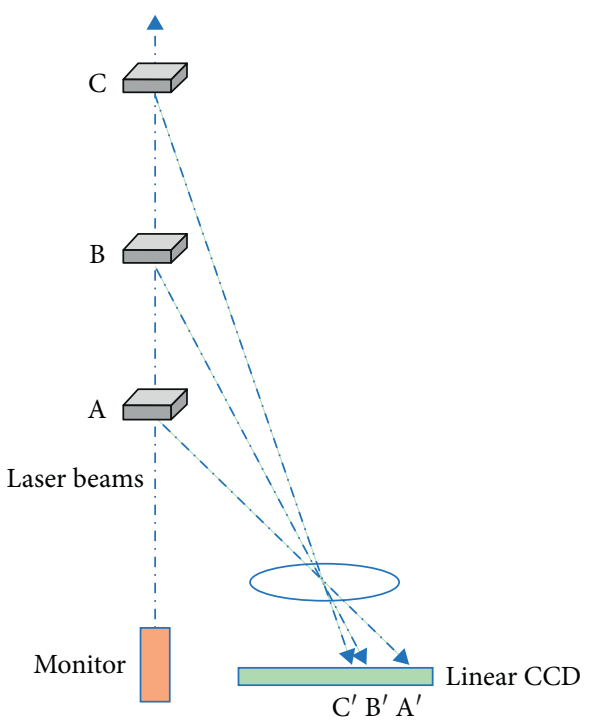

FIgURE 4: Principle diagram of laser monitoring of denudation amount.

\subsection{Analysis of Original Monitoring Data Curve}

4.1.1. Roof Pressure Monitoring Curve. The data of typical monitoring points were taken and the curve was drawn, as presented in Figure 6.

The curve demonstrated the monitoring data of a twomonth period from the end of April to the end of June. It could be observed that no noticeable fluctuation exited. The pressure value fluctuated continuously near the prestress value applied at the initial stage of column installation, presenting certain regularity, while indicating that the roof stability was good during the monitoring period.

\subsubsection{Deformation Curve of Roof Monitored by Grating.} The deformation curve of roof grating monitoring was drawn, as presented in Figure 7.

Since the roof grating monitoring points were installed at the outer and inner surface of the roof rock at the same time, the deformation characteristics of the roof rock were reflected from the multidimensional point of view. Although the curve presented a slight downward trend, its monitoring accuracy was in millimeters. The data was extremely accurate, proving meaningless. From the phenomenon of curve representation, the roof deformation was quite low, while the roof is in a stable state.

4.1.3. GNSS Monitoring Curve. The curve of GNSS monitoring data is presented in Figure 8.

The absolute accuracy of GNSS monitoring data was relatively low, but it could reflect the change of relative coordinates at a large area in real-time all day long. The longterm monitoring data of Yuanjue rock cave were reflected on the curve and regularly fluctuated around the value of 0 constantly. It could be observed that the monitoring point did not sustain horizontal displacement, which also demonstrated that the entire Yuanjue rock cave had not been affected by large geological forces and would not be damaged by geological activities within a short period of time. However, the monitoring method required longer in time and higher range of monitoring data, to produce the activity characteristics of the geological area. Also, InSAR [21] technology could be utilized to monitor the geological area.

4.1.4. Laser Monitoring Curve of Denudation Amount. The laser monitoring data of denudation amount and the temperature change value in a coordinate system were drawn. Consequently, the typical monitoring curve was produced, as presented in Figure 9.

The data of denudation demonstrated that the displacement of the roof changed highly and the maximum deformation was $3.5 \mathrm{~mm}$. Within the past 800 years, the denudation of the roof of Yuanjue rock cave reached the centimeter level. During the monitoring period, the data presented high amount of denudation, but insignificant amount of rock debris was found on-site, due to denudation. From the curve trend, the displacement presented a decreasing trend in the late August. It was observed that the deformation curve had a strong correlation with temperature. Consequently, it could be observed that no severe denudation occurred. At first, it was speculated that the roof might be arched, due to the alternation of seasons, high temperatures throughout summer, and temperature stress. After entering autumn and winter, due to the decrease of temperature and the recovery of deformation, the curve would decline.

However, according to the monitoring data of roof stress, the roof did not sustain high displacement due to temperature change, while the grating monitoring data tended to be stable, which did not indicate that this roof high displacement.

After the experiment, it was confirmed that the ablation laser monitor was highly affected by the temperature throughout long-term monitoring, while the built-in program did not rectify the drift caused by the temperature change. Subsequently, the curve changed abnormally.

\subsection{Indoor Constant Temperature and Humidity Machine Experiment}

4.2.1. Experimental Principle. According to the aforementioned inference, it was speculated that, under the influence of temperature, the monitoring data of laser monitor of denudation amount presented deviations, while the data should be corrected with temperature compensation. For this reason, the indoor Constant temperature and humidity machine experiment was set up. Under different temperatures, the ranging variables were controlled, the data obtained were regressed, and the temperature compensation denudation amount equation of the laser monitor was obtained. The experimental principle is presented in Figure 10.

In order to ensure the accuracy and effectiveness of the experiment, a relatively flat surface for measurements was fixed on top of the constant temperature and humidity 


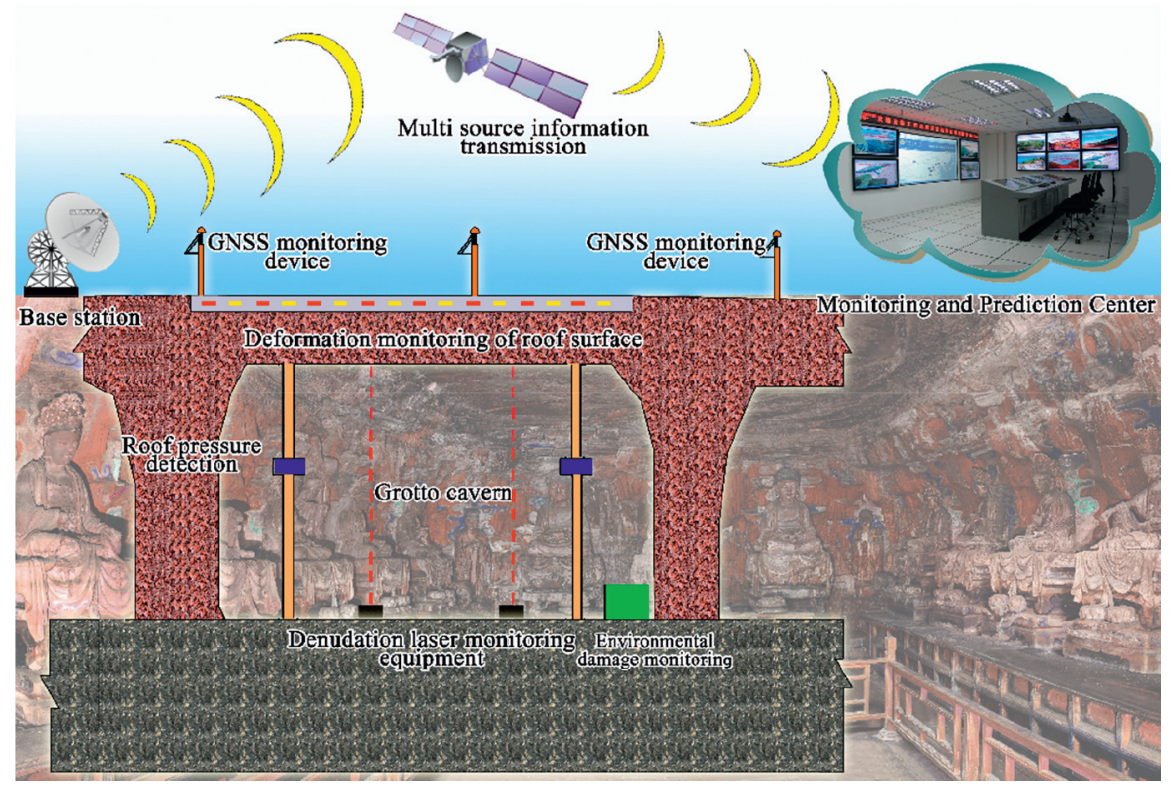

FIGURE 5: Schematic diagram of the integrated monitoring system.

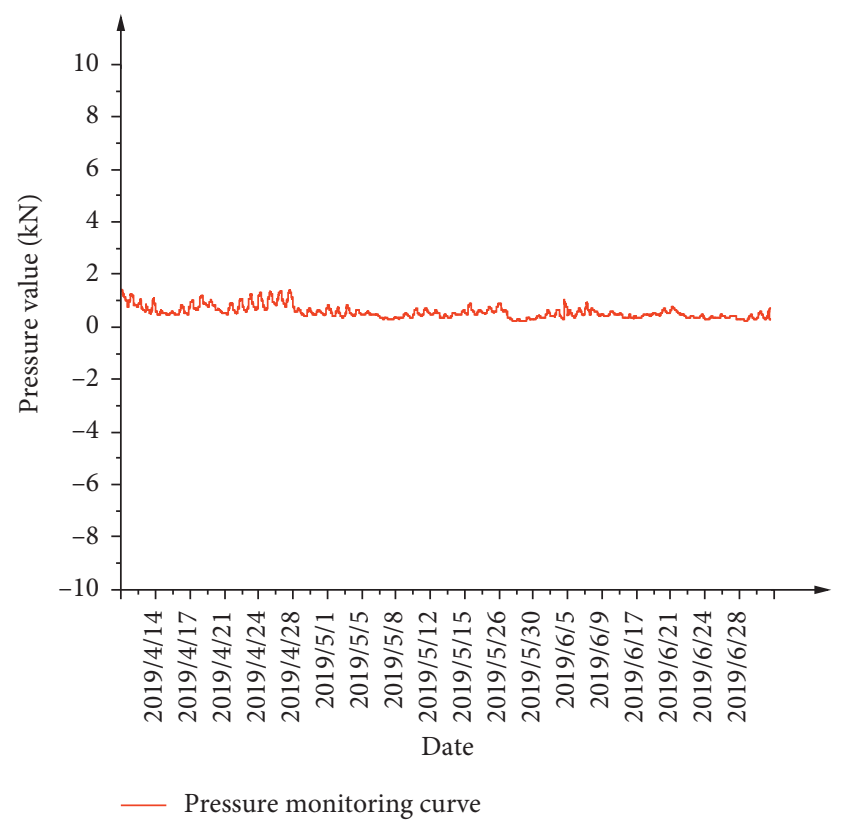

Figure 6: Roof pressure monitoring curve.

machine. During experimentation, data measurements were carried out after the constant temperature and humidity machine reached the preset temperature for 3 hours, to reduce the temperature lagging effect of the monitor.

Simultaneously, in order to ensure the applicability of the experimental results, the experimental conditions should be reduced to the site environmental conditions as much as possible. The humidity should be controlled at above $85 \%$ and the temperature range should be $5^{\circ} \mathrm{C} \sim 40^{\circ} \mathrm{C}$. After many positive and negative temperature gradient experiments, the variables should be controlled, while the same surface to be measured should be measured multiple times. The scatter

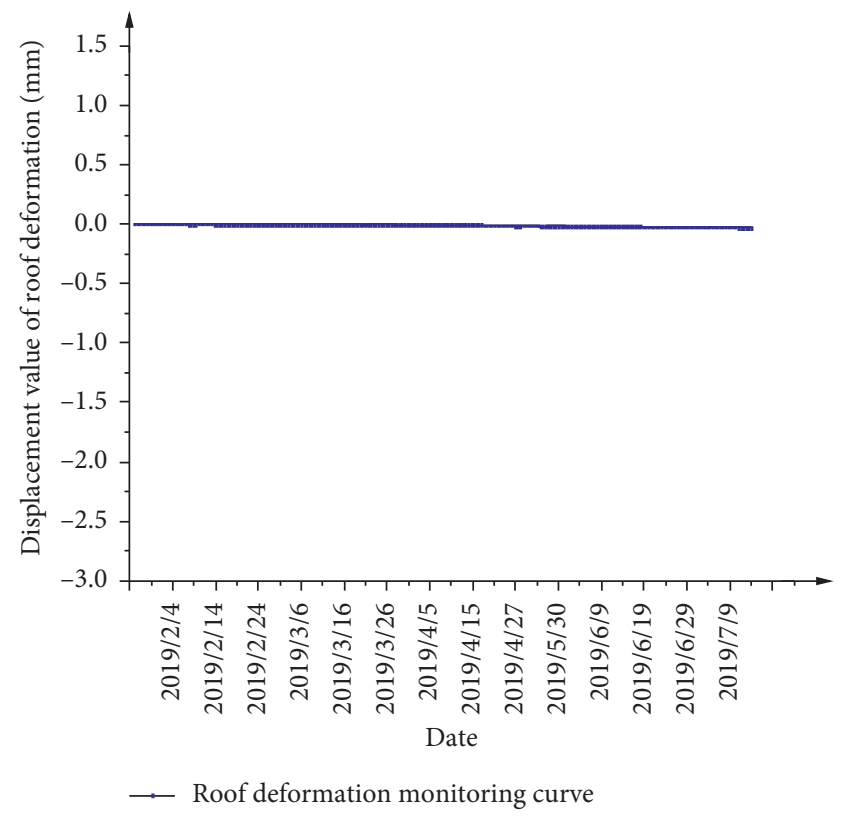

FIGURE 7: Monitoring curve of roof deformation through the grating monitoring method.

diagram of the relationship among the data and the temperature gradient is presented in Figure 11.

Linear regression was carried out for the curve, as presented in Figure 11. Theoretically, the intercept of the fitting curve should be 0 , but the intercept of the fitting expression was caused by the computer fitting algorithm and experimental accuracy. Since the intercept magnitude was low, it was not included, whereas only the slope value was taken and the equation was obtained:

$$
L_{2}=\left(L_{1}-\Delta T \times 0.058 \mathrm{~mm}\right)-L_{0},
$$




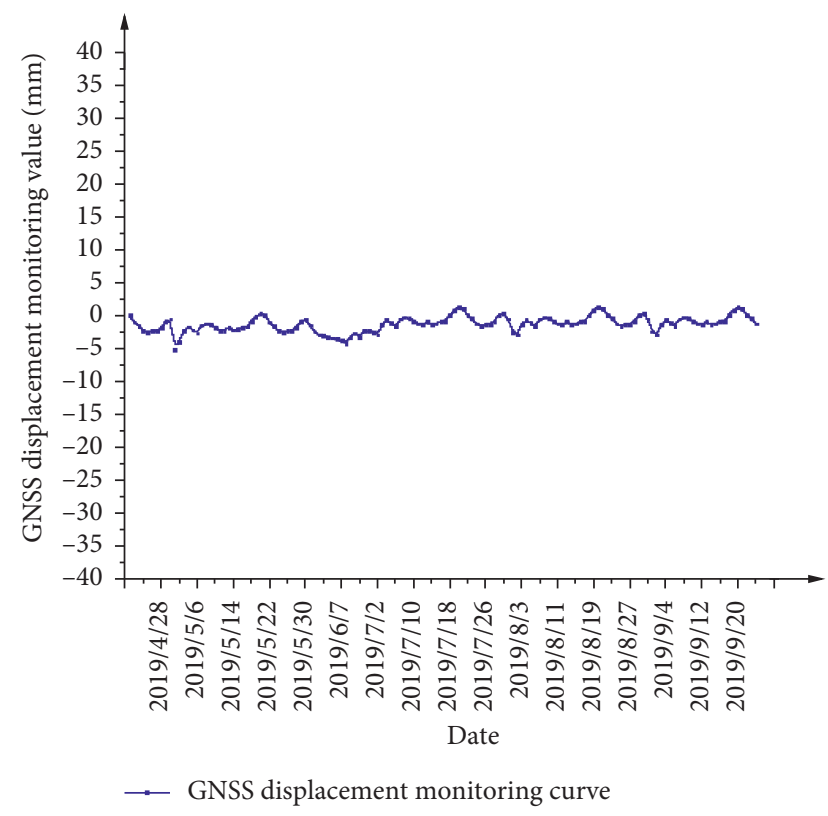

FIGURE 8: GNSS displacement monitoring curve.

where $L_{0}$ : initial value of linear distance between monitoring equipment and measured rock mass $(\mathrm{mm}) ; L_{1}$ : measured value of deformation before temperature compensation $(\mathrm{mm}) ; L_{2}$ : calculated value of deformation after temperature compensation $(\mathrm{mm})$; and $\triangle \mathrm{T}$ : temperature gradient $\left({ }^{\circ} \mathrm{C}\right)$.

4.2.2. Measurement Data Correction. The aforementioned equation was utilized to compensate the temperature of the original measurement data and to produce the green curve, as presented in Figure 12. Although the curve still fluctuated after compensation, the small-scale change had no practical significance, while the curve trend tended to be stable, which proved that the roof sustained insignificant displacement and was basically stable throughout the entire monitoring period.

The corrected deformation curve was consistent with the change curve of roof stress and the grating monitoring. The curve was in a reasonable fluctuation range, which proved that the roof did not sustain high deformation and was in a relatively stable state.

\section{Comprehensive Evaluation Method of Roof Stability}

5.1. Research on Comprehensive Evaluation Method. Due to the complexity of data types and the high amount of data, the experts could not only be relied on, to carry out qualitative evaluation on the safety of cavern roof. A comprehensive evaluation method should be established to quantify and standardize the evaluation standards. Of course, the knowledge of experts should surely be used to make the evaluation standards more practical [22].

Defining parameters in evaluation criteria, GNSS accumulated the displacement value:

$$
G=\sqrt{\left(x_{1}-x_{0}\right)^{2}+\left(y_{1}-y_{0}\right)^{2}+\left(z_{1}-z_{0}\right)^{2}},
$$

where $x_{1}, y_{1}$, and $z_{1}$ are the final measurement coordinates and $x_{0}, y_{0}$, and $z_{0}$ are the initial coordinates.

Accumulated value of roof grating deformation monitoring:

$$
J=\frac{J_{A}+J_{A^{\prime}}}{2}
$$

where $J_{A}$ is the measurement data of fixed-point grating on the upper surface of the roof and $J_{A^{\prime}}$ is the measurement data of fixed-point grating on the lower surface of the roof.

Change of roof pressure:

$$
F=F^{\prime}-F_{0}
$$

where $F^{\prime}$ is the final measured value and $F_{0}$ is the initial prestress value.

Cumulative value of denudation amount (displacement):

$$
D=D^{\prime}-D_{0}
$$

where $D^{\prime}$ is the final measurement and $D_{0}$ is the initial measurement.

Based on this, a local stability evaluation equation was established:

$$
y=f(J, F, D)+g(G),
$$

where $f(J, F, D)$ is the cumulative value of roof grating deformation monitoring in a monitoring area and the relationship between the change of roof pressure and the cumulative value of denudation (displacement). $g(G)$ is the GNSS cumulative displacement function because it does not belong to any of the divided roof zone, and the function relationship was independently set.

Because we do not care about the stress of every point of roof, we only need to know its failure trend, so we use the structural mechanics model. Since a crack penetrated the entire cave at the east of Yuanjue rock cave, as presented with a purple dotted line in Figure 2, the top plate could be regarded as a plate model with one end fixed and one end simply supported. The roof was divided into several beams with one end fixed and one end simply supported along the short edge of the plate, while the bending moment is presented in Figure 13, and the equation was

$$
\begin{aligned}
& M_{A}=\frac{q l^{2}}{8}, \\
& M_{B}=\frac{q l^{2}}{8} .
\end{aligned}
$$

Similarly, the cantilever beam could be simplified along the long side and the bending moment at the fixed end was

$$
M_{C}=\frac{1}{2} q l^{2} \text {. }
$$

The bending moment is presented in Figure 13.

According to the moment distribution characteristics and failure modes of each model, the roof was divided into three 


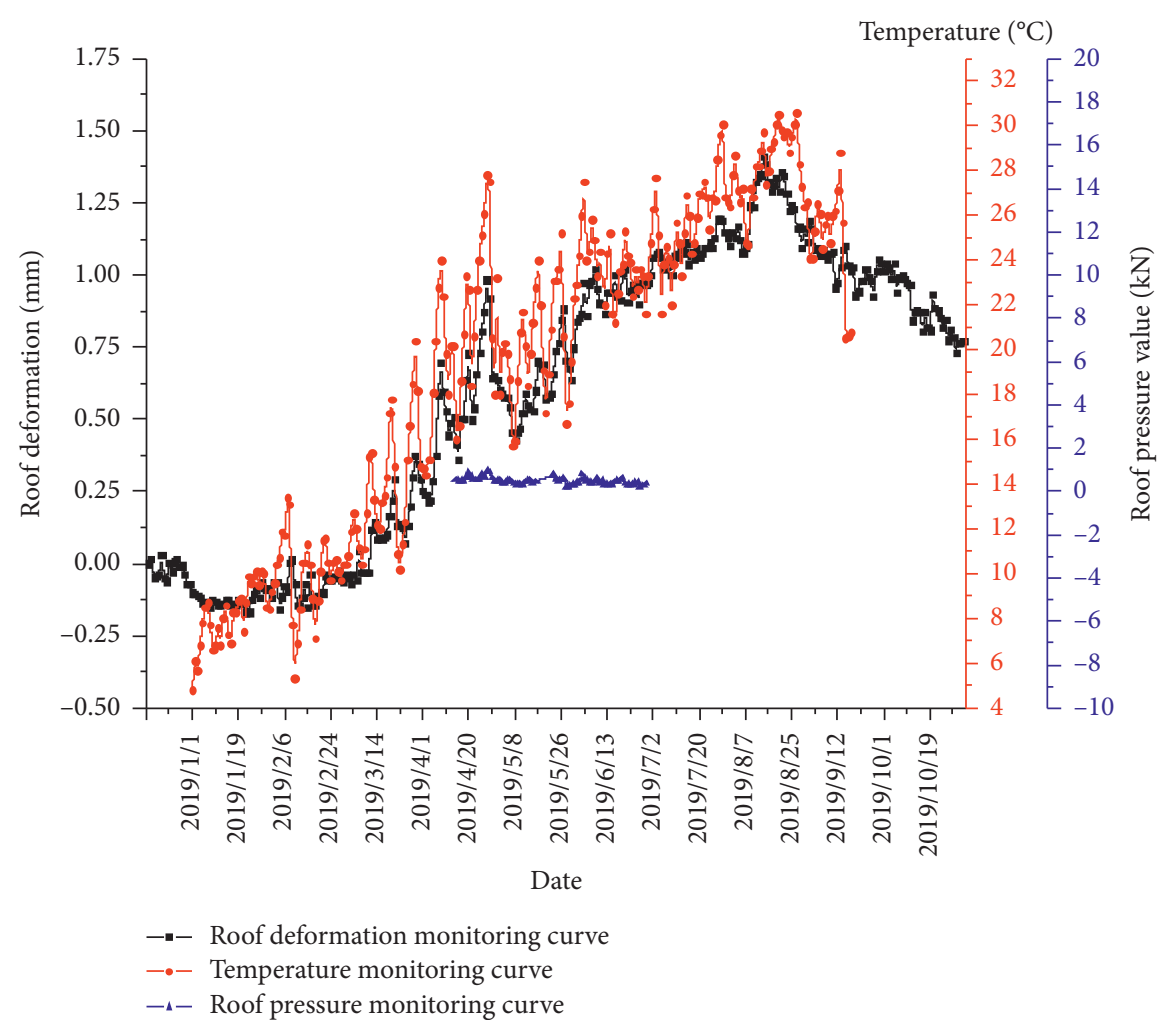

Figure 9: Relationship between roof displacement and temperature.

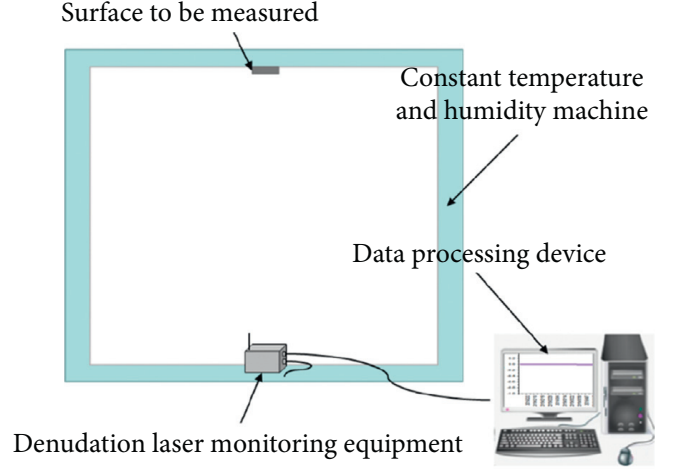

Figure 10: Schematic diagram of constant temperature and humidity machine experiment.

types of areas and 12 blocks, as presented in Figure 14. From (1) to (3), the bearing capacity of the area was weakened and the flexural deformation increased. Consequently, the influence on the roof stability correspondingly increased and the weight of the data in the larger sequence block was correspondingly higher.

The stability of block $i$ was evaluated through equation (6):

$$
\begin{aligned}
y_{i} & =f(J, F, D)+g(G), \\
& =\sum_{\varphi=J, D, F} W_{\varphi} \times \varphi_{i}+\sum_{j=1}^{n} W_{G} \times G_{j} .
\end{aligned}
$$

where $W_{J}$ is the weight of the accumulated value of roof grating deformation monitoring, $W_{F}$ is the weight of the accumulated

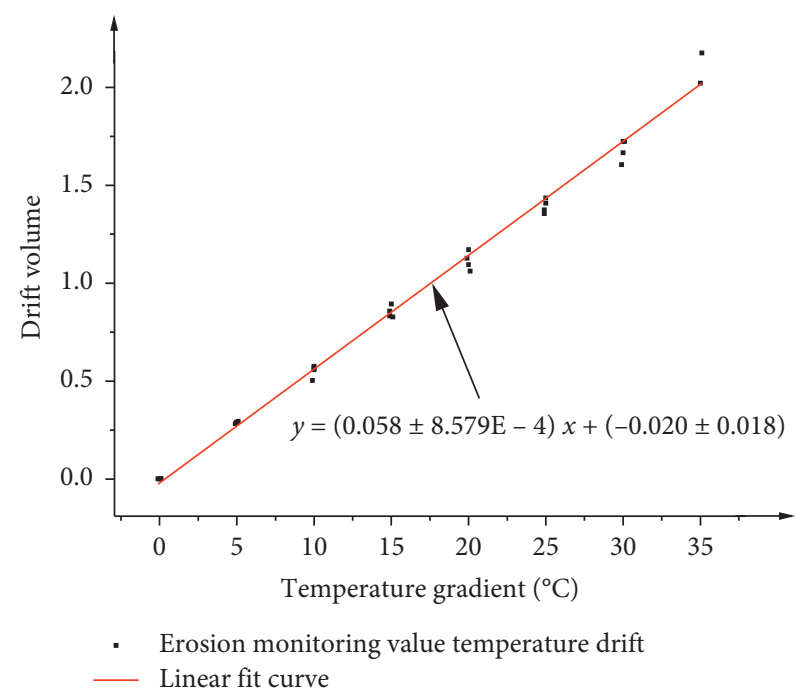

Figure 11: Temperature drift and linear fitting curve.

value of roof pressure, $W_{D}$ is the weight of the accumulated value of denudation amount (displacement), and $W_{G}$ is the weight of the accumulated displacement value of GNSS. According to the expert scoring method in AHP (AHP: Analytic hierarchy process), ten experts were consulted, the scoring results were normalized and finally $W_{J}=25 \%$, $W_{F}=25 \%, W_{D}=35 \%$, and $W_{G}=15 \%$ were determined.

After the stability evaluation of a single block, it was necessary to evaluate the overall stability of the roof. In 


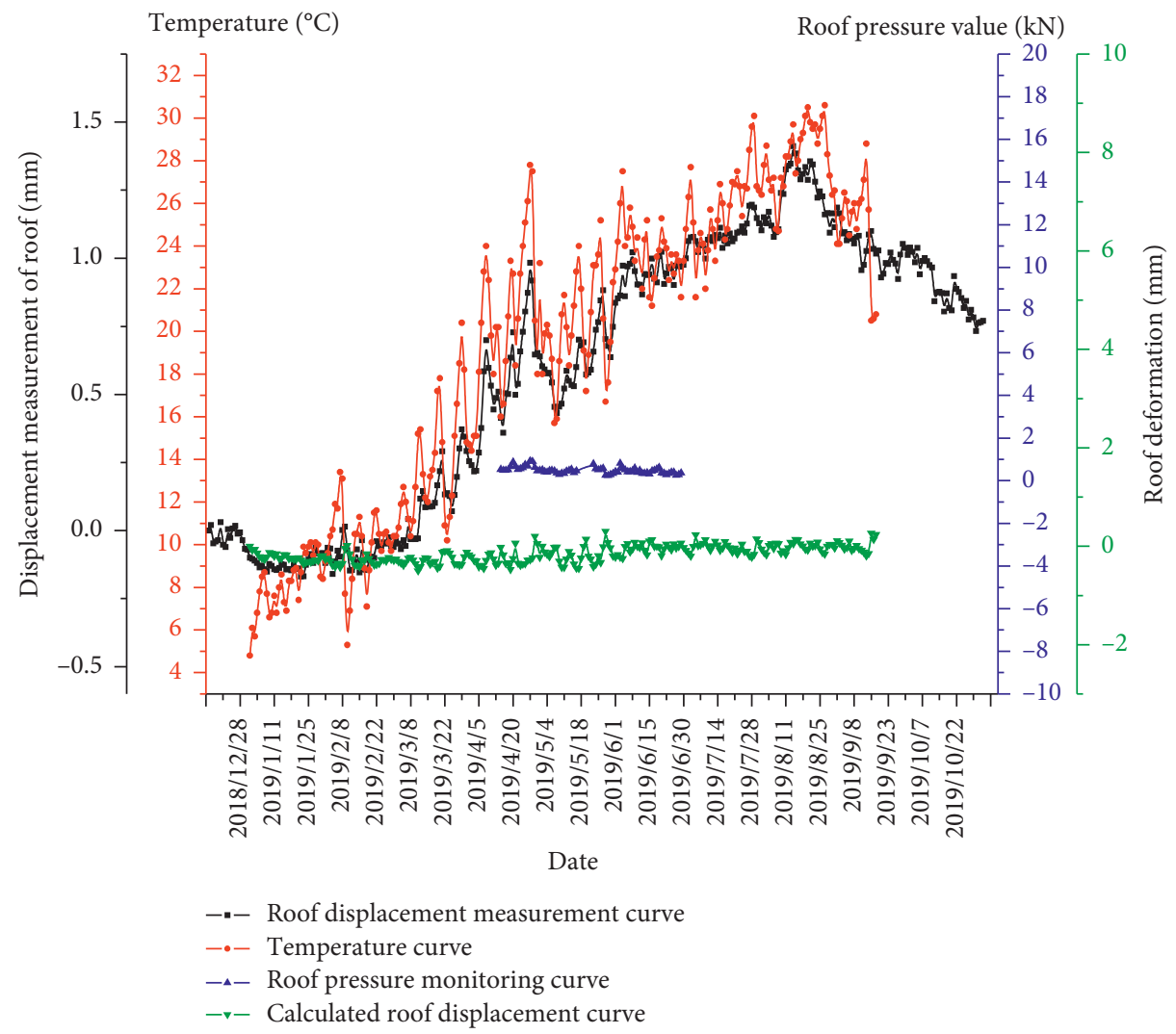

FIgURE 12: Curve comparisons after temperature drift correction.

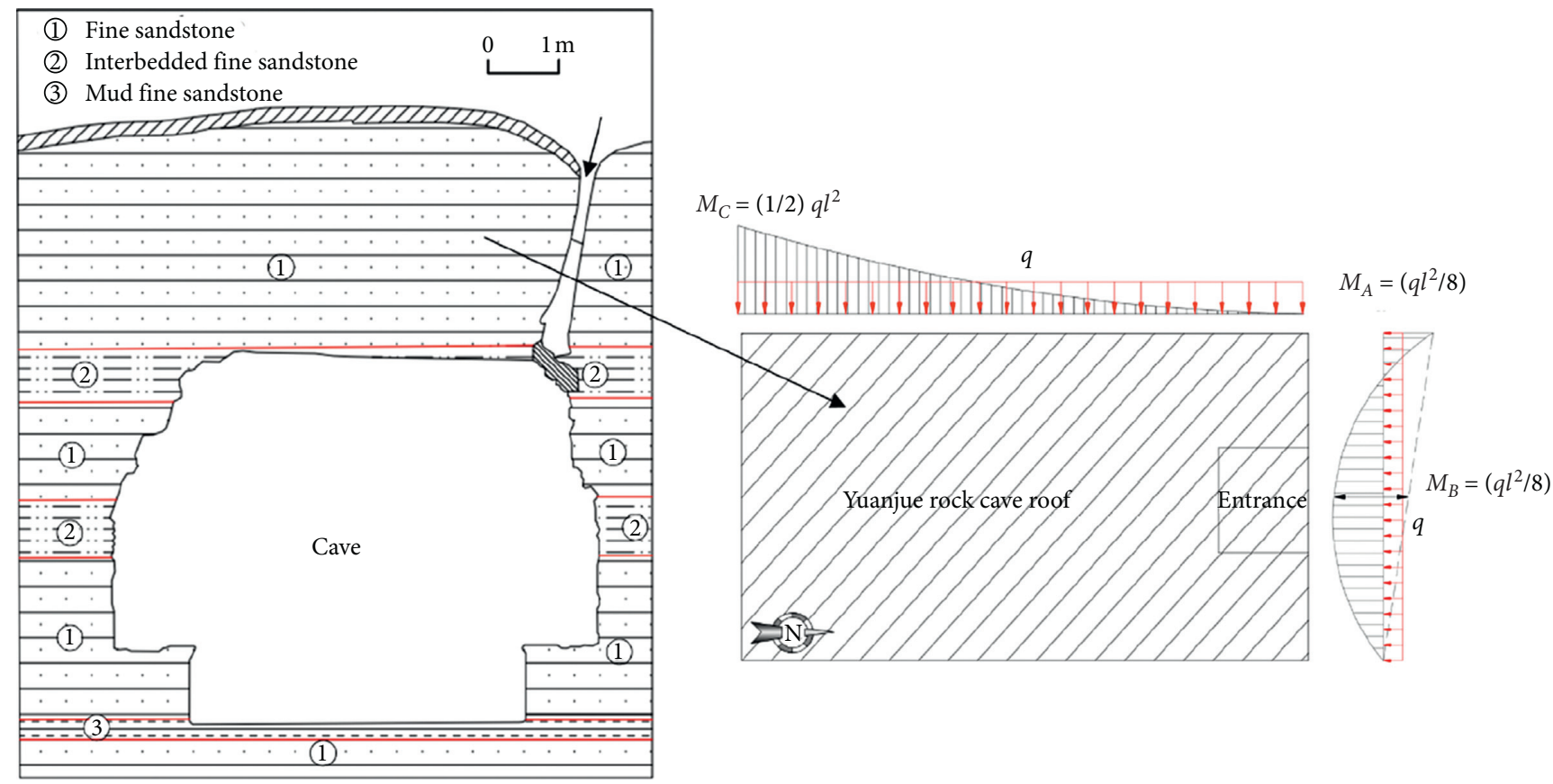

FIgURE 13: Sectional view of tunnel and simplified diagram of roof bending moment.

order to highlight the different influence factors of different blocks on stability, the weighted method was also adopted:

$$
Q=\frac{\sum_{i=1}^{N} y_{i} \times \psi_{i}}{\beta \sum_{i=1}^{N} y_{i}},
$$




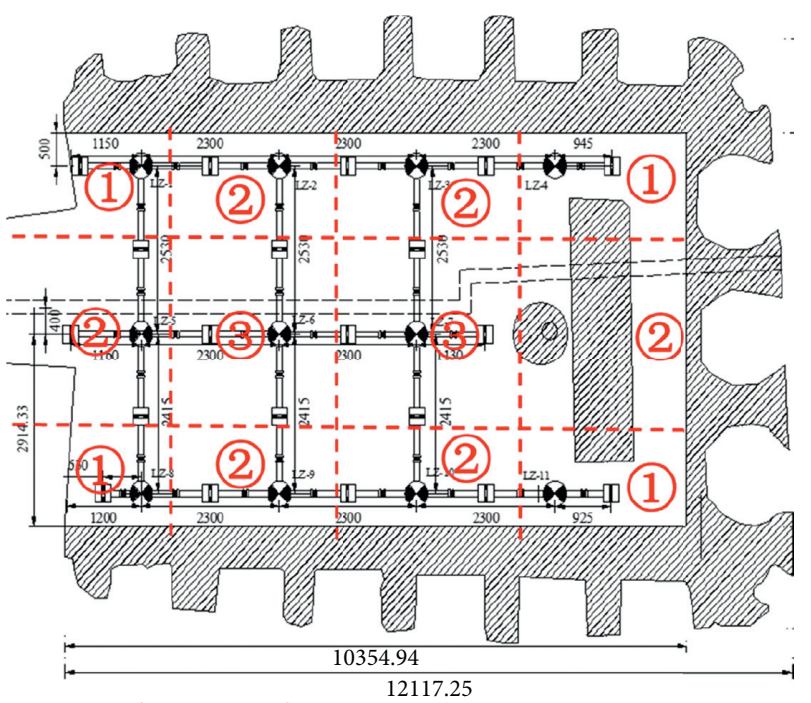

FIgURE 14: Schematic diagram of roof division.

TABle 1: Monitoring data and evaluation parameters of Yuanjue rock cave.

\begin{tabular}{|c|c|c|c|c|c|c|c|}
\hline Grade & $\mathrm{J}(\mathrm{mm})$ & $\begin{array}{c}\mathrm{F} \\
(\mathrm{kN})\end{array}$ & $\mathrm{D}(\mathrm{mm})$ & $\begin{array}{l}\text { Weight } \\
\text { division }\end{array}$ & $\begin{array}{c}\text { GNSS: } \mathrm{G}(\mathrm{mm}) \text { (note: not included in } \\
\text { weight division) }\end{array}$ & $\mathrm{Y}(\beta=1.7)$ & \\
\hline 1 & -0.0413 & 0.26 & -2.3006 & 3 & 0 & $\mathrm{y} 1$ & -0.75054 \\
\hline 2 & -0.0357 & 0.2 & -3.0686 & 2 & 0 & $\mathrm{y}^{2}$ & -1.03294 \\
\hline 3 & -0.039 & 0.901 & -2.668 & 2 & & $\mathrm{y} 3$ & -0.7183 \\
\hline 4 & -0.0287 & 0.407 & & 2 & & $\mathrm{y} 4$ & 0.094575 \\
\hline 5 & -0.0391 & 0.637 & -2.1476 & 2 & & y5 & -0.60219 \\
\hline 6 & & 0.989 & -1.3677 & 1 & & y6 & -0.23145 \\
\hline 7 & -0.0363 & 0.416 & -2.0625 & 3 & & y7 & -0.62695 \\
\hline 8 & -0.0419 & 0.61 & -2.8312 & 1 & & y8 & -0.8489 \\
\hline 9 & & 0.846 & & 1 & & y9 & 0.2115 \\
\hline 10 & -0.0294 & -0.05 & -1.9538 & 1 & & y10 & -0.70368 \\
\hline 11 & & 0 & & 2 & & y11 & 0 \\
\hline 12 & -0.0482 & & & 2 & & y12 & -0.01205 \\
\hline $\begin{array}{l}\text { Weight } \\
\text { value }\end{array}$ & 0.25 & 0.25 & 0.35 & & 0.15 & $\begin{array}{l}\text { Comprehensive evaluation } \\
\text { value }\end{array}$ & 1.305019 \\
\hline
\end{tabular}

Note: $\mathrm{J}$ was used for the accumulated value of grating monitoring deformation; $\mathrm{F}$ was used for accumulated value of roof pressure monitoring; $\mathrm{D}$ was used for accumulative value of laser monitoring for denudation amount.

where $\psi$ is the weight of each block, (1) block $\psi=1$, (2) block $\psi=2$, and (3) block $\psi=3 ; \beta$ is the evaluation score of the expert group $(1<\beta<2)$, for better site evaluation, $\beta$ takes the larger value, and for worse site evaluation, $\beta$ takes the smaller value. No apparent deformation occurred within Yuanjue rock cave, except certain amount of exfoliated rock debris only. All data demonstrated that the stability of the cave was good, while the evaluation was $\beta=1.7$. If there no special damage would occur to the roof, the following parameters could be utilized to determine the stability:

$$
\begin{cases}Q<1.5, & \text { Stable, } \\ 1.5<Q<2, & \text { Less stable, } \\ Q>2, & \text { Instable. }\end{cases}
$$

5.2. Example Calculation. The collected data of Yuanjue rock cave were sorted out, as presented in Table 1. According to the aforementioned method, the data were analyzed and calculated. Finally, the comprehensive evaluation value of Yuanjue rock cave was $Q=1.3$, which was lower than 1.5. It could be concluded that the roof stability of Yuanjue rock cave was good within the short term. This was also consistent with the results of various monitoring data, but from other observation results, the weathering rate of the surface rock mass was accelerated, resulting in the strength reduction of the surface rock mass, presenting exfoliations. In the long run, the exfoliation phenomena of surface rock mass would also have an impact on the stability of the roof of the Yuanjue rock cave. Consequently, the study on the weathering mechanism of the surface rock mass should be carried out later.

\section{Conclusions}

(1) When the new system was in practice, through the monitoring curve of denudation amount comparison with the temperature curve, it was found that, 
during the long-term monitoring, the curve drifts were highly influenced by the temperature. While in the built-in data processing system of the system, the temperature compensation command should be added to ensure the monitoring data accuracy.

(2) Through the experimental study of the indoor constant temperature and humidity machine, the deformation correction parameters and the deformation correction equation were obtained. Through the displacement curve of roof and other monitoring data analysis after the temperature effect elimination and according to the bending mode of the roof, a new determination method was proposed. Through the evaluation parameter calculation of the roof, it was deduced that the deformation of the roof was a longterm process with small changes within a short period of time. At present, the deformation of the roof is in a relatively stable state. However, due to the environmental damage and accelerated weathering of the surface rock mass, the phenomena of weakening and exfoliation occurred, which might still pose a threat to the roof stability.

(3) The protection of Yuanjue cave should be started with the weathering acceleration mechanism study of the corresponding surface rock mass and the reduction of environmental damage factors on the weakening of the tunnel wall rock mass. The artificial reinforcement scheme was utilized as auxiliary means.

(4) A lot of high-tech were applied to this research so that we could monitor the deformation accurately without contact. This is a new study idea and method to protect the cultural relics. This study on the roof stability monitoring and evaluation of Yuanjue cave provided substantial practice basis for the research and protection of similar cultural relics in the near future.

\section{Data Availability}

The data used to support the findings of this study are included within the article.

\section{Conflicts of Interest}

The authors declare that they have no conflicts of interest.

\section{Acknowledgments}

This work was supported by the National Key Research and Development Project (Grant no. 2016YFC0600901), Fundamental Research Funds for the Key Laboratory of Geotechnical and Underground Engineering (Tongji University), Ministry of Education (Grant no. KLE-TJGEB1905), Zhejiang Province Key R\&D Projects (Grant no. 2019C03104), Fundamental Research Funds for the Central Universities (Grant no. 2015QB02), and Dazu District Science and Technology Commission Project (Grant no. DZKJ2018ABB1011).

\section{References}

[1] J. H. Wang and J. Q. Chen, "Current status and future development of cave temples protection in China," Southeast Culture, vol. 261, no. 1, pp. 6-14, 2018.

[2] X. X. Zhang, W. Z. Ren, X. W. Wu, H. K. Liu, and G. J. Fu, "Microscopic and mechanical characteristics of rocks near big buddha bay rock carvings in Dazu," Journal of Wuhan University of Science and Technology (Natural Science Edition), vol. 40, no. 4, pp. 314-320, 2017.

[3] C. H. Fu and C. Y. Shi, "Research on dynamic damage characteristics of country rock of mogao grottoes under earthquake loading," Northwestern Seismological Journal, vol. 26, no. 3, pp. 266-273, 2004.

[4] B. L. Gao, H. X. Zhang, and Z. F. Yang, "Study on crack development mechanism and reinforcement support of the roof of the No.3 cavern in Longyou grottos," Journal of Engineering Geology, vol. 28, no. 3, pp. 565-573, 2020.

[5] W. X. Ding, J. P. Chen, X. T. Feng, and H. Zhou, "Study on weathering characteristics of surrounding rock in Longmen cavern," Rock and Soil Mechanics, vol. 25, no. 1, pp. 145-148, 2004.

[6] Z. Y. Wang, Z. F. Yang, Y. P. Li, L. Q. Zhang, and J. Zhen, "Numerical simulation and back analysis of rheologic fracture process of Longyou grotto roof," Chinese Journal of Rock Mechanics and Engineering, vol. 25, no. 1, pp. 9-14, 2006.

[7] L. H. Li, J. L. Liu, Y. Fu, Z. F. Yang, and Z. J. Zhang, "Eight years test results of weathering rates and time limit prediction of chisel imprints on pelitic siltstone inside five Longyou caverns," Journal of Engineering Geology, vol. 20, no. 5, pp. 706-714, 2012.

[8] Z. Y. Hu, X. Y. Fan, Z. R. Zhu, Z. R. Chang, and X. Liu, “A study on prediction of rock stability for protection of Dazu grotto," Underground Space, vol. 4, pp. 267-276, 1995.

[9] D. Liu, Z. Gu, R. Liang et al., "Impacts of pore-throat system on fractal characterization of tight sandstones," Geofluids, vol. 2020, no. 9, 17 pages, Article ID 4941501, 2020.

[10] H. Y. Pan, D. W. Yin, N. Jiang, and Z. G. Xia, "Crack initiation behaviors of granite specimens containing crossing-doubleflaws with different lengths under uniaxial loading," Advances in Civil Engineering, vol. 2020, Article ID 8871335, 13 pages, 2020.

[11] J. Wang, Y. Zhang, Z. Qin, S. Song, and P. Lin, "Analysis method of water inrush for tunnels with damaged waterresisting rock mass based on finite element method-smooth particle hydrodynamics coupling," Computers and Geotechnics, vol. 126, Article ID 103725, 2020.

[12] X. Wang, C. Liu, S. Chen, L. Chen, K. Li, and N. Liu, "Impact of coal sector's de-capacity policy on coal price," Applied Energy, vol. 265, Article ID 114802, 2020.

[13] G. Feng, X. C. Wang, M. Wang, and Y. Kang, "Experimental investigation of thermal cycling effect on fracture characteristics of granite in a geothermal-energy reservoir," Engineering Fracture Mechanics, vol. 235, pp. 1-16, Article ID 107180, 2020.

[14] P. Sun, S. J. Yan, Y. Dou, J. Q. Chen, and K. He, "Simulation of fracture grouting test for sandstones of Dazu rock carvings," Journal of Yangtze River Scientific Research Institute, vol. 33, no. 6, pp. 134-139, 2016.

[15] B. F. Zhang and S. W. Jiang, "Preliminary exploration of water seepage disease on Big Buddha Bay of Dazu rock carving," China Cultural Heritage Scientific Research, vol. 1, pp. 68-71, 2016. 
[16] Z. X. Zhang, L. S. Fu, J. S. Yao, and D. Y. Wang, "Lithological characters of carved sandstone in Dazu," Journal of Chongqing Jianzhu University, vol. 17, no. 2, pp. 58-62, 1995.

[17] J. T. Chen, J. H. Zhao, S. C. Zhang, Y. Zhang, F. Yang, and M. Li, "An experimental and analytical research on the evolution of mining cracks in deep floor rock mass," Pure and Applied Geophysics, vol. 2020, no. 1, 2020.

[18] C. Zhu, M. C. He, M. Karakus, X. B. Cui, and Z. G. Tao, "Investigating toppling failure mechanism of anti-dip layered slope due to excavation by physical modelling," Rock Mechanics and Rock Engineering, vol. 53, pp. 5029-5050, 2020.

[19] B. Chen, S. C. Zhang, Y. Y. Li, Z. K. Li, and H. J. Zhou, "Physical simulation study of crack propagation and instability information discrimination of rock-like materials with faults," Arabian Journal of Geosciences, vol. 13, p. 966, 2020.

[20] Z. Tao, Y. Wang, C. Zhu, and H. Xu, "Mechanical evolution of constant resistance and large deformation anchor cables and their application in landslide monitoring," Bulletin of Engineering Geology and the Environment, vol. 78, no. 7, pp. 4787-4803, 2019.

[21] R. S. Heli, S. Q. Xiong, H. F. Nie, S. N. Liang, Z. R. Qi, and J. Z. Yang, "Remote sensing technology and its application in geological exploration," Acta Geologica Sinica, vol. 85, no. 11, pp. 1699-1743, 2011.

[22] W. Y. Xu, Z. M. Jiang, and A. C. Shi, "Slope stability analysis using fuzzy sets theory," Chinese Journal of Geotechnical Engineering, vol. 25, no. 4, pp. 409-413, 2003. 